\title{
Indices for extreme events in projections of anthropogenic climate change
}

\author{
J. Sillmann • E. Roeckner
}

Received: 19 July 2006 / Accepted: 23 May 2007 / Published online: 4 August 2007

(C) Springer Science + Business Media B.V. 2007

\begin{abstract}
Indices for temperature and precipitation extremes are calculated on the basis of the global climate model ECHAM5/MPI-OM simulations of the twentieth century and SRES A1B and B1 emission scenarios for the twenty-first century. For model evaluation, the simulated indices representing the present climate were compared with indices based on observational data. This comparison shows that the model is able to realistically capture the observed climatological large-scale patterns of temperature and precipitation indices, although the quality of the simulations depends on the index and region under consideration. In the climate projections for the twenty-first century, all considered temperature-based indices, minimum Tmin, maximum Tmax, and the frequency of tropical nights, show a significant increase worldwide. Similarly, extreme precipitation, as represented by the maximum 5-day precipitation and the 95th percentile of precipitation, is projected to increase significantly in most regions of the world, especially in those that are relatively wet already under present climate conditions. Analogously, dry spells increase particularly in those regions that are characterized by dry conditions in present-day climate. Future changes in the indices exhibit distinct regional and seasonal patterns as identified exemplarily in three European regions.
\end{abstract}

\section{Introduction}

Nowadays a major worry of mankind is anthropogenic climate change and its socioeconomic impacts. Global surface temperature has significantly risen during the last century and will continue to rise unless greenhouse gas emissions are drastically reduced (Houghton et al. 2001). The impacts of climate change are manifold and vary regionally, even locally, in their severity. However, immediate damages to humans and their properties are not obviously caused by gradual changes in temperature or precipitation but mainly by so-called extreme climate events. The rare occurrence of extremes makes it necessary to

J. Sillmann $(\square) \cdot$ E. Roeckner

Max Planck Institute for Meteorology, Bundesstrasse 53, 20146 Hamburg, Germany

e-mail: jana.sillmann@zmaw.de 
investigate long data records to determine significant changes in the frequency and intensity of extreme events. To this end, coupled atmosphere-ocean general circulation models (AOGCM) are appropriate tools to simulate past, present, and future climate states. Thus, AOGCM are able to generate long time series that can be used for model evaluation and also for analyses of possible future changes in extreme events.

There are various methods to characterize extreme events, for instance by means of percentile-, threshold- or duration-based indices, or by analyzing the statistical behavior of the tail of a weather element's probability distribution. The focus of this study is on the non-parametric approach. Indices for climate extremes based on daily temperature and precipitation data were defined by an international committee to assess extremes in temperature and precipitation and to make a global and multi-model comparison possible (Folland et al. 1999; Karl et al. 1999; Nicholls and Murray 1999). Frich et al. (2002) defined ten key indices, which should be statistically robust with fairly short return periods and represent a wide variety of climate aspects. Several studies subsequently focused on the analysis of this set of key indices. However, the definitions and usefulness of some of these indices, although meant to be globally valid, became the subject of discussion and, as a result, definitions of some indices as well as their calculations were reconsidered (Alexander et al. 2006; Zhang et al. 2005; Tebaldi et al. 2006; Kiktev et al. 2003; Haylock and Goodness 2004, etc.). Several studies to date have concentrated on the analysis of indices for climate extremes based on observational data from weather stations (e.g., Frich et al. 2002; Klein Tank and Koennen 2003; Klein Tank 2004), while others focused primarily on the changes of extremes in future climate projections (e.g., Meehl et al. 2000; Meehl and Tebaldi 2004; Tebaldi et al. 2006).

The objectives of the present study are, first, to investigate whether our model is able to capture the observed spatial and temporal patterns of extreme temperature and precipitation events and, second, to analyze the changes of extreme indices in future climate projections. The paper is organized as follows. The model and the experiments are briefly described in Section 2, followed by a discussion of the climate indices selected for this study in Section 3. The results are presented in Section 4, which has two parts. In Section 4.1 the simulated indices are compared with the observed ones, whilst the changes obtained in future climate projections are presented in Section 4.2. A discussion of the main results in Section 5 concludes this paper.

\section{Model description and experiments}

All model-based indices described in this paper were calculated from data generated with the coupled AOGCM ECHAM5/MPI-OM developed at the Max Planck Institute for Meteorology (Jungclaus et al. 2006). The atmospheric component ECHAM5 (Roeckner et al. 2003) has a horizontal resolution of 63 wave numbers in spectral space (T63), corresponding to $1.875^{\circ} \times 1.875^{\circ}$ in grid-point space, and 31 vertical levels. The oceanic component of the coupled model (MPI-OM) is a GCM with integrated sea ice model (Marsland et al. 2003). It has a nominal horizontal resolution of $1.5^{\circ}$ and 40 vertical levels. The coupled model does not employ flux adjustments.

The model experiments analyzed in this study include a 500-year pre-industrial control run $(\mathrm{CON})$, three twentieth century simulations $(20 \mathrm{C})$ initialized at different states of $\mathrm{CON}$, and three realizations of the IPCC scenarios A1B and B1, respectively, initialized at year 2000 of the respective $20 \mathrm{C}$ experiments. In CON, the greenhouse gas concentrations were kept constant at levels for the year 1860 and anthropogenic sulfate aerosols were set to zero. 
In the $20 \mathrm{C}$ runs, greenhouse gases $\left(\mathrm{CO}_{2}, \mathrm{CH}_{4}, \mathrm{~N}_{2} \mathrm{O}, \mathrm{CFC}, \mathrm{O}_{3}\right)$ and sulfate aerosols were prescribed year to year according to observations and chemical transport model results, respectively. In the future scenario experiments, greenhouse gas and sulfate aerosol concentrations were prescribed year to year according to the scenarios A1B and B1 in the "Special Report on Emissions Scenarios" (SRES; Nakicenovic et al. 2000) of the Intergovernmental Panel on Climate Change (IPCC). A1B is the part of the A1 family that describes a balance across all energy sources, resulting in a total radiative forcing of about $6 \mathrm{Wm}^{-2}$ in year 2100 compared to pre-industrial times (Houghton et al. 2001). B1 describes a storyline with rapid changes in economic structures toward a service and information economy with reductions in material intensity and the introduction of clean and resource-efficient technologies, resulting in a total radiative forcing of about $4 \mathrm{Wm}^{-2}$ in year 2100 (Houghton et al. 2001).

\section{Methodology}

Daily 2 m maximum and minimum temperature (Tmax and Tmin, respectively) as well as precipitation data were used to calculate 27 indices for climate extremes as defined by the Expert Team on Climate Change Detection Monitoring and Indices (ETCCDMI), which is jointly sponsored by the World Meteorological Organization (WMO) Commission of Climatology (CCI) and the Climate Variability and Predictability (CLIVAR) project (Peterson 2005). An excerpt of these indices can be seen in Table 1. CLIVAR also provided the basic computer software used for the calculation of these indices (FclimDex), which was modified for the needs of gridded climate model data. The threshold-based indices that have to be calculated relative to a base period were calculated according to the bootstrap method (Zhang et al. 2005).

All indices mentioned in this paper were calculated on an annual basis for the three ensemble members and ensemble means of the $20 \mathrm{C}$ and the scenario simulations, respectively. Additionally, some of the model-based indices were calculated on a monthly basis (cf. Section 4.2.3). For the comparison of the 20C model runs with observations, we used the indices for climate extremes based on data from worldwide weather observation stations as described in Alexander et al. (2006). The Hadley Centre for Climate Prediction and Research provides these indices on an annual basis for the time period 1951-2003 and gridded to a spatial resolution of $3.75^{\circ}$ longitude by $2.5^{\circ}$ latitude (Hadley Centre Observational Datasets 2006). Those indices will be referred to as HadEX indices in the following. It is important to note that all observation-based indices were first calculated for all weather stations and then interpolated onto the latitude-longitude grid, whereas the model-based indices were calculated from the variables representative for the whole gridbox area. These methodological differences are likely to cause systematic differences in the probability distribution of spatially inhomogeneous data such as precipitation, for example.

The present analysis is limited to a few key indices (indicated in bold letters in Table 1). The selection was based on the following criteria. The indices should be robust and plausible considering the comparably coarse model resolution and the information deducible from the indices should be useful for climate change impact studies. The minimum Tmin (TNn) and maximum Tmax (TXx) as well as the number of tropical nights (TR) represent the temperature indices for climate extremes in this paper. TNn and TXX correspond to the absolute temperature extremes within a year. Tropical nights are defined as days with Tmin greater than $20^{\circ} \mathrm{C}$. TR was chosen to provide information about possible heat stress for organisms. During heat wave events, higher nighttime temperatures can 
Table 1 Excerpt of the extreme indices recommended by the ETCCDMI (http://cccma.seos.uvic.ca/ ETCCDMI/list_27_indices.html)

\begin{tabular}{|c|c|c|c|c|}
\hline \multicolumn{2}{|c|}{ ID } & \multirow{2}{*}{$\begin{array}{l}\text { Indicator name } \\
\text { Cool nights }\end{array}$} & \multirow{2}{*}{$\begin{array}{l}\text { Indicator definitions } \\
\text { Let } \operatorname{Tn}_{\mathrm{ij}} \text { be the daily minimum temperature on day } i \text { in } \\
\text { period } j \text { and let } \operatorname{Tn}_{\mathrm{in}} 10 \text { be the calendar day } 10 \text { th percentile } \\
\text { centered on a 5-day window. The percentage of days in a } \\
\text { year is determined where } \operatorname{Tn}_{\mathrm{ij}}<\operatorname{Tn}_{\mathrm{in}} 10\end{array}$} & \multirow{2}{*}{$\frac{\text { Units }}{\%}$} \\
\hline 1 & TN10p & & & \\
\hline 2 & TX10p & Cool days & $\begin{array}{l}\text { Let } \mathrm{Tx}_{\mathrm{ij}} \text { be the daily maximum temperature on day } i \text { in } \\
\text { period } j \text { and let } \mathrm{Tx}_{\mathrm{in}} 10 \text { be the calendar day 10th percentile } \\
\text { centered on a 5-day window. The percentage of days is } \\
\text { determined where } \mathrm{Tx}_{\mathrm{ij}}<\mathrm{Tx}_{\mathrm{in}} 10\end{array}$ & $\%$ \\
\hline 3 & TN90p & Warm nights & $\begin{array}{l}\text { Let } \operatorname{Tx}_{\mathrm{ij}} \text { be the daily minimum temperature on day } i \text { in } \\
\text { period } j \text { and let } \operatorname{Tn}_{\mathrm{in}} 90 \text { be the calendar day 90th percentile } \\
\text { centered on a 5-day window. The percentage of days is } \\
\text { determined where } \operatorname{Tn}_{\mathrm{ij}}>\operatorname{Tn}_{\mathrm{in}} 90\end{array}$ & $\%$ \\
\hline 4 & TX90p & Warm days & $\begin{array}{l}\text { Let } \mathrm{Tx}_{\mathrm{ij}} \text { be the daily maximum temperature on day } i \text { in } \\
\text { period } j \text { and let } \mathrm{Tx}_{\mathrm{in}} 90 \text { be the calendar day 90th } \\
\text { percentile centered on a 5-day window. The percentage of } \\
\text { days is determined where } \operatorname{Tx}_{\mathrm{ij}}>\mathrm{Tx}_{\mathrm{in}} 90\end{array}$ & $\%$ \\
\hline
\end{tabular}

5 TXx Max Tmax

6 TXn Min Tmax

7 TNx Max Tmin

8 TNn Min Tmin

9 FD Frost days

10 ID Ice days

11 SU Summer days

12 TR Tropical nights

13 GSL Growing Season length

14 DTR Diurnal temperature range

15 RX1day Max 1-day precipitation amount
Let $\mathrm{Tx}_{\mathrm{kj}}$ be the daily maximum temperature in month $k,{ }^{\circ} \mathrm{C}$ period $j$. The minimum daily maximum temperature each month is then $T X x_{k j}=\max \left(T X_{k j}\right)$

Let $\mathrm{Tx}_{\mathrm{kj}}$ be the daily maximum temperature in month $k, \quad{ }^{\circ} \mathrm{C}$ period $j$. The maximum daily maximum temperature each month is then $\mathrm{TXx}_{\mathrm{kj}}=\min \left(\mathrm{TX}_{\mathrm{kj}}\right)$

Let $\mathrm{Tn}_{\mathrm{kj}}$ be the daily minimum temperature in month $k, \quad{ }^{\circ} \mathrm{C}$ period $j$. The maximum daily minimum temperature each month is then $\mathrm{TNx}_{\mathrm{kj}}=\min \left(\mathrm{TN}_{\mathrm{kj}}\right)$

Let $\mathbf{T n}_{\mathrm{kj}}$ be the daily manimum temperature in month $k$, period $j$. The minimum daily maximum temperature each month is then $\mathbf{T N n}_{\mathrm{kj}}=\min \left(\mathbf{T N}_{\mathrm{kj}}\right)$

Let $\operatorname{Tn}_{\mathrm{ij}}$ be the daily minimum temperature on day $i$ in days period $j$. Count the number of days where $\operatorname{Tn}_{\mathrm{ij}}<0{ }^{\circ} \mathrm{C}$

Let $\mathrm{Tx}_{\mathrm{ij}}$ be the daily maximum temperature on day $i$ in days period $j$. Count the number of days where $\operatorname{Tx}_{\mathrm{ij}}<0{ }^{\circ} \mathrm{C}$

Let $\mathrm{Tx}_{\mathrm{ij}}$ be the daily maximum temperature on day $i$ in days period $j$. Count the number of days where $\operatorname{Tx}_{\mathrm{ij}}>25{ }^{\circ} \mathrm{C}$

Let $\operatorname{Tn}_{\mathrm{ij}}$ be the daily minimum temperature on day $i$ in days $\operatorname{period} \boldsymbol{j}$. Count the number of das where $\mathbf{T n}_{\mathrm{ij}}>20^{\circ} \mathrm{C}$

Let $\mathrm{T}_{\mathrm{ij}}$ be the mean temperature on day $i$ in period $j$. Count days the number of days between the first occurrence of at least six consecutive days with $\mathrm{T}_{\mathrm{ij}}>5^{\circ} \mathrm{C}$ and the first occurrence after 1st July $(\mathrm{NH})$ or 1 st January $(\mathrm{SH})$ of at least six consecutive days with $\mathrm{T}_{\mathrm{ij}}<5{ }^{\circ} \mathrm{C}$

Let $\mathrm{Tn}_{\mathrm{ij}}$ and $\mathrm{Tx}_{\mathrm{ij}}$ be the daily minimum and maximum $\quad{ }^{\circ} \mathrm{C}$ temperature respectively on day $I$ in period $j$. If $I$ represents the number of days in $j$, then $\operatorname{DTR}_{\mathrm{j}}=\sum\left(\mathrm{Tx}_{\mathrm{ij}}-\mathrm{Tn}_{\mathrm{ij}}\right) / I$

Let $\mathrm{RR}_{\mathrm{kj}}$ be the precipitation amount for the 1-day interval $\mathrm{mm}$ ending $k$, period $j$. Then maximum 1-day values for period $j$ are $\mathrm{Rx} 1 \mathrm{day}_{\mathrm{j}}=\max \left(\mathrm{RR}_{\mathrm{kj}}\right)$ 
Table 1 (continued)

\begin{tabular}{|c|c|c|c|c|}
\hline ID & & Indicator name & Indicator definitions & Units \\
\hline 16 & RX5day & $\begin{array}{l}\text { Max 5-day } \\
\text { precipitation amount }\end{array}$ & $\begin{array}{l}\text { Let } \mathrm{RR}_{\mathrm{kj}} \text { be the precipitation amount for the } 5 \text {-day } \\
\text { interval ending } k \text {, period } j \text {. Then } \operatorname{maximum} 5 \text {-day } \\
\text { values for period } j \text { are } \operatorname{Rx} 5 \mathrm{day}_{\mathrm{j}}=\max \left(\mathrm{RR}_{\mathrm{kj}}\right)\end{array}$ & mm \\
\hline 17 & SDII & $\begin{array}{l}\text { Simple daily intensity } \\
\text { index }\end{array}$ & $\begin{array}{l}\text { Let } \mathrm{RR}_{\mathrm{wj}} \text { be the daily precipitation amount on wet days, } \\
\mathrm{RR} \geq 1 \mathrm{~mm} \text { in period } j .{ }_{\mathrm{W}} W \text { represents number of wet } \\
\text { days in } j \text {, then }{ }_{\mathrm{SDII}}=\frac{\sum_{\mathrm{w}=1} \mathrm{RR}_{\mathrm{wj}}}{\mathrm{W}}\end{array}$ & $\mathrm{mm} / \mathrm{d}$ \\
\hline 18 & $\mathrm{R} 10$ & $\begin{array}{l}\text { Number of heavy } \\
\text { precipitation days }\end{array}$ & $\begin{array}{l}\text { Let } \mathrm{RR}_{\mathrm{ij}} \text { be the daily precipitation amount on day } i \text { in } \\
\text { period } j . \text { Count the number of days where } R \mathrm{Rij} \geq 10 \mathrm{~mm}\end{array}$ & days \\
\hline 19 & $\mathrm{R} 20$ & $\begin{array}{l}\text { Number of very heavy } \\
\text { precipitation days }\end{array}$ & $\begin{array}{l}\text { Let } \mathrm{RR}_{\mathrm{ij}} \text { be the daily precipitation amount on day } i \text { in } \\
\text { period } j \text {. Count the number of days where } \mathrm{RR}_{\mathrm{ij}}=20 \mathrm{~mm}\end{array}$ & days \\
\hline 20 & CDD* & Consecutive dry days & $\begin{array}{l}\text { Let } \mathrm{RR}_{\mathrm{ij}} \text { be the precipitation amount on day } i \text { in period } \\
j \text {. Count the largest number of consecutive days where } \\
\mathrm{RR}_{\mathrm{ij}}>1 \mathrm{~mm}\end{array}$ & days \\
\hline 21 & CWD & Consecutive wet days & $\begin{array}{l}\text { Let } \mathrm{RR}_{\mathrm{ij}} \text { be the daily precipitation amount on day } i \text { in } \\
\text { period } j . \text { Count the largest number of consecutive days } \\
\text { where } \mathrm{RR}_{\mathrm{ij}}>1 \mathrm{~mm}\end{array}$ & days \\
\hline 22 & R95p & Very wet days & $\begin{array}{l}\text { Let } R R_{w j} \text { be the daily precipitation amount on a wet day } \\
w\left(R R_{i j} \geq 1.0 \mathrm{~mm}\right) \text { in period } j \text { and let } R R_{w n} 95 \text { be the } 95 \text { th } \\
\text { percentile of precipitation on wet days in the 1961-1990 } \\
\text { period. If } W \text { represents the number of wet days in the } \\
\text { period, then } R 95 p_{j}=\sum R R_{w j} \text { where } R R_{w j}>R R_{w n} 95\end{array}$ & $\mathbf{m m}$ \\
\hline 23 & PRCPTOT & $\begin{array}{l}\text { Annual total wet-day } \\
\text { precipitation }\end{array}$ & $\begin{array}{l}\text { Let } \mathrm{RR}_{\mathrm{ij}} \text { be the daily precipitation amount on day } i \text { in } \\
\text { period } j . \text { If } I \text { represents the number of days in } j \text {, then } \\
\text { PRCPTOT }_{\mathrm{j}}=\Sigma(\mathrm{RR} \text { ij })\end{array}$ & $\mathrm{mm}$ \\
\hline
\end{tabular}

Indices that are described in detail in this study are highlighted in bold letters.

*Spell indices

increase the heat stress experienced by organisms. An increase in the frequency of tropical nights could thus be an indicator for more heat stress.

The selected key indices for precipitation are the maximum 5-day precipitation amount during a year (RX5day), the 95th percentile of precipitation on wet days (R95p), and the number of consecutive dry days during a year (CDD). Days with precipitation above (below) $1 \mathrm{~mm}$ are defined as wet (dry) days, respectively. For spell indices (in Table 1 marked with an asterisk), such as CDD and consecutive wet days (CWD), it has to be mentioned that if a spell lasts longer than a year it is counted against the year in which the spell ends. RX5day can be used as a flood indicator because severe floods, on the space scales considered here, are generally not caused by a single heavy thunderstorm event, but more likely, by long-lasting heavy precipitation events that are extended over a large region. R95p characterizes the upper tail of the precipitation distribution. CDD is the only index that refers to the dry part of the year and can indicate regions vulnerable to droughts. Real drought conditions, however, are caused by more complex conditions than captured by CDD, e.g. interactions of precipitation deficits as well as soil and land use characteristics (Tebaldi et al. 2006). The selected key indices were also chosen by Alexander et al. (2006), Tebaldi et al. (2006), Kiktev et al. (2003), Easterling et al. (1997), and Karl et al. (1993), thus enabling a comparison with their results. 


\section{Results}

\subsection{Comparison of model- and observation-based indices for extreme events}

The comparison of model- and observation-based indices was carried out on the basis of global maps and 53-year time series (1951-2003). First, the model-based indices were interpolated onto the Hadley Center HadCM3 model grid $\left(3.75^{\circ} \times 2.5^{\circ}, 96 \times 73\right.$ grid boxes). Furthermore, the time-dependent mask of missing grid values in the HadEX dataset was applied to the model-based indices when displaying global maps of time averages and calculating time series. All indices mentioned in Table 1 were analyzed on an annual basis. However, results are presented only for the key indices shown in boldface in Table 1. The global maps allow a comparison of the large-scale patterns of the individual indices. The time series show spatial averages of the indices for three European regions as defined in Table 2. When comparing the time series of HadEX and model-based indices, not only the ensemble mean is considered, but also the range of the three ensemble members of the $20 \mathrm{C}$ model simulations.

\subsubsection{Temperature}

In most regions, the maximum Tmax (TXx) shown in Fig. 1a,b is well captured by the model. However, TXx at high northern latitudes is systematically underestimated by typically $10^{\circ} \mathrm{C}$ and also on the Tibetan Plateau. Additional indices based on Tmax reveal corresponding features at high northern latitudes. For example, the number of ice days (ID) is too high and the number of summer days (SU) is much too low. On the other hand, the minimum Tmax (TXn) is in good agreement with the HadEX data (not shown). Similarly, both the spatial distribution and the absolute values of the minimum Tmin (TNn) are very well simulated (Fig. 1c,d). Other indices based on Tmin, e.g. frost days (FD), also show good agreement between the model and HadEX data (not shown). The diurnal temperature range (DTR) (not shown), which is the difference between daily Tmax and Tmin, is generally underestimated, especially at high northern latitudes. However, the global spatial patterns of DTR in the model show a good agreement with the HadEX data. Although the large-scale distribution of tropical nights (TR) is reasonably well represented by the model, there are differences in the details (Fig. 1e,f). For example, the area with TR $>150$ days is more extended in the model (Southeast Asia, Australia, southern USA). Similarly, the cold regions with $\mathrm{TR}<1$ day are too widespread (western USA, southern Europe, Tibetan Plateau, southern part of South America) so that the transition zones cover a smaller area than in the observations.

For a more quantitative assessment of model errors, the temporal evolution of observed and simulated indices is shown in Fig. 2 for three European regions (cf., Table 2). Consistent with the spatial pattern of TXx (cf., Fig. 1a,b) the model simulation deteriorates with increasing northern latitude (Fig. 2a-c). Whereas TXx is generally close to the

Table 2 Spatial definition of three European regions

Only land points are considered.

\begin{tabular}{lll}
\hline Region & Longitudes & Latitudes \\
\hline Southern Europe & $12 \mathrm{~W}-40 \mathrm{E}$ & $35 \mathrm{~N}-45 \mathrm{~N}$ \\
Central Europe & $12 \mathrm{~W}-40 \mathrm{E}$ & $45 \mathrm{~N}-55 \mathrm{~N}$ \\
Northern Europe & $12 \mathrm{~W}-40 \mathrm{E}$ & $55 \mathrm{~N}-70 \mathrm{~N}$
\end{tabular}



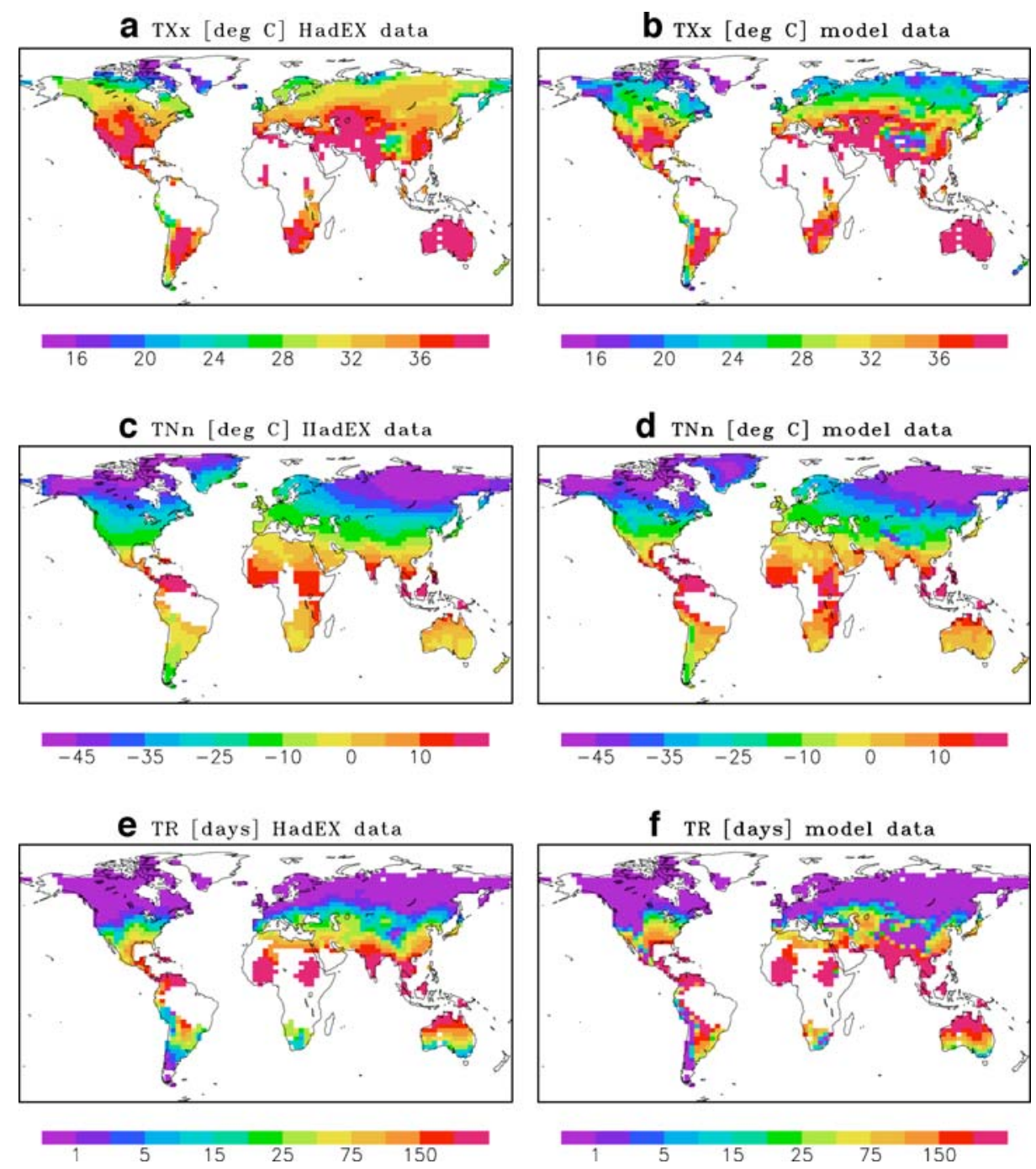

Fig. 1 Time averaged temperature-based indices (1951-2003) for HadEX data (left) and model data (right). Compared are the maximum Tmax $(\mathbf{a}, \mathbf{b})$, the minimum $\operatorname{Tmin}(\mathbf{c}, \mathbf{d})$ and the tropical nights $(\mathbf{e}, \mathbf{f})$. The model data represent the respective ensemble means of three $20 \mathrm{C}$ realizations. Missing values in the HadEX data are masked out in the model data as well

observations in southern Europe, larger differences of about $-2^{\circ}$ can be found in central Europe and, in particular, in northern Europe where the error becomes as large as $-4^{\circ} \mathrm{C}$. In comparison with the HadEX data, the model overestimates the number of ice days (ID) especially in northern Europe and underestimates the number of summer days (SU) in all European regions (not shown). Consistent with the spatial pattern of TNn (cf. Fig. 1c,d), the HadEX data are mostly within the ensemble spread of the model data in all European regions (Fig. 2d-f). In northern Europe, the model overestimates the number of frost days (not shown). The diurnal temperature range (DTR; not shown) is underestimated in all regions, but mostly in northern Europe (about $2.5^{\circ} \mathrm{C}$ on average). The number of tropical nights TR (Fig. $2 \mathrm{~g}-\mathrm{i}$ ) is just about $50 \%$ of the observed one in central Europe, whereas in 

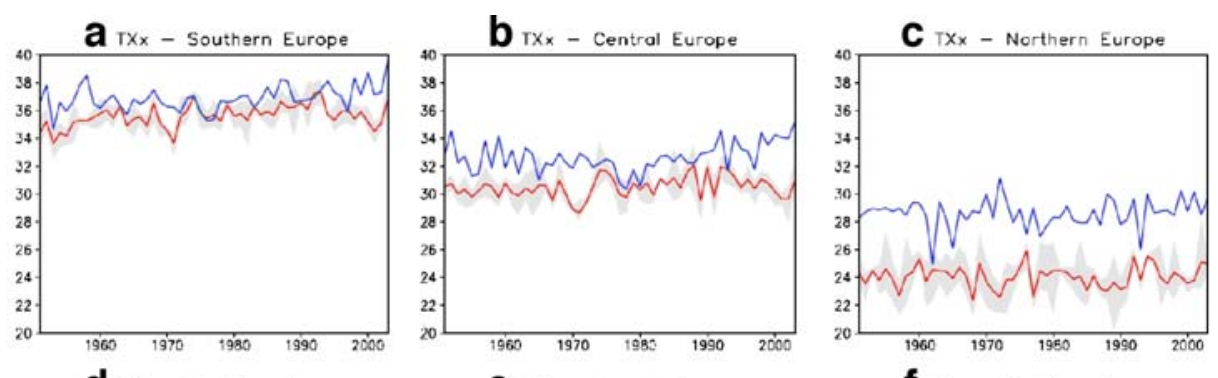

d TNn - Southern Europe

e iNn - Central Europe

$f_{\mathrm{TNn}}$ - Northern Europe
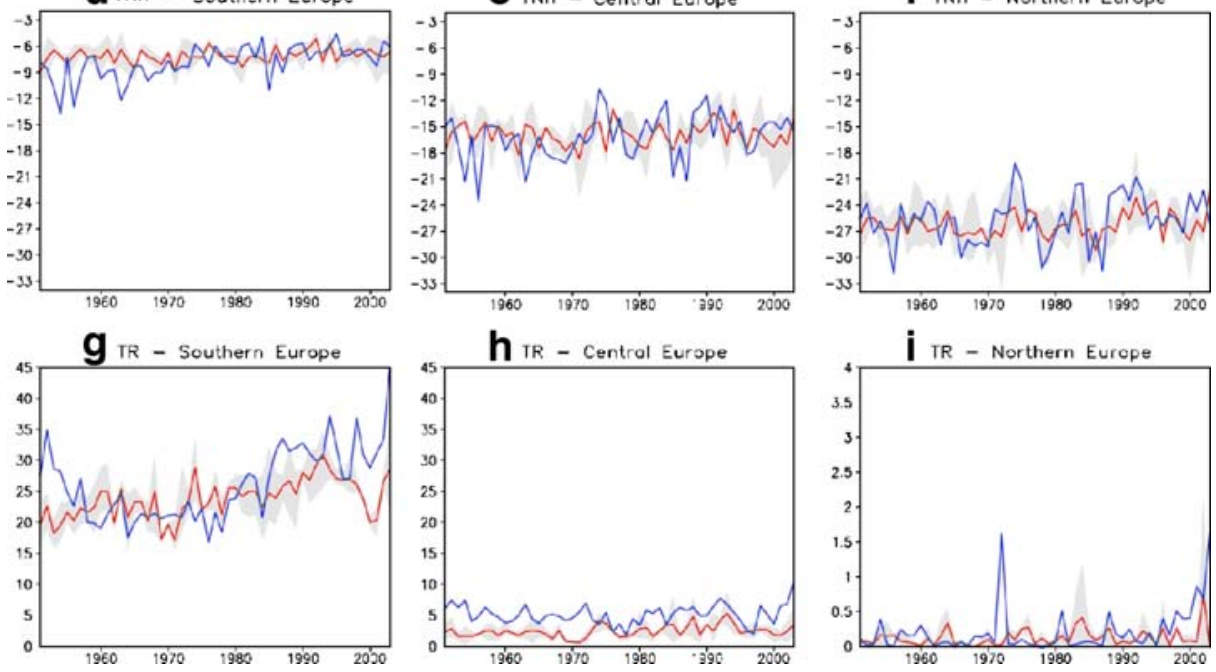

Fig. 2 Time series (1951-2003) of spatially averaged (land only) temperature-based HadEX indices (blue) and the ensemble mean of the model-based indices (red) for three regions in Europe (cf., Table 2). Compared are the maximum $\operatorname{Tmax}\left({ }^{\circ} \mathrm{C}\right)$ in the three regions $(\mathbf{a}, \mathbf{b}, \mathbf{c})$, the minimum $\operatorname{Tmin}\left(\mathbf{d}, \mathbf{e}, \mathbf{f} ;{ }^{\circ} \mathrm{C}\right)$ and the tropical nights (g, h, i; days). The shading indicates the spread of the three $20 \mathrm{C}$ realizations

northern Europe tropical nights are very rare events in both the observations and simulations. For southern Europe, the interpretation of the TR time series is more ambiguous. Here the simulated time-mean TR is close to the observed one, but the decline in the observed record until about 1970, and the marked increase thereafter, is missing in the model simulations. The question whether these multi-decadal changes are due to natural variability or induced by external forcing cannot be answered with confidence.

The model captures the threshold-based indices cool nights (TN10p), warm nights (TN90p), cool days (TX10p), and warm days (TX90p; not shown) reasonably well in all European regions. However, since the actual thresholds needed to calculate these indices were not provided with the HadEX data, a meaningful comparison was not possible. Hence, these threshold-based indices are excluded from this study.

\subsubsection{Precipitation}

The spatial distribution of the maximum 5-day precipitation (RX5day) is generally well represented in the model (Fig. 3a,b). However, the model slightly underestimates the absolute values of RX5day in most regions, except in the western part of North America. 
a RX5day [mm] HadEX data

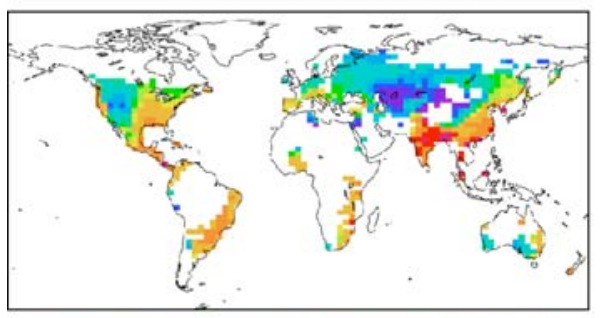

20

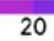

C R95p [mm] HadEX data

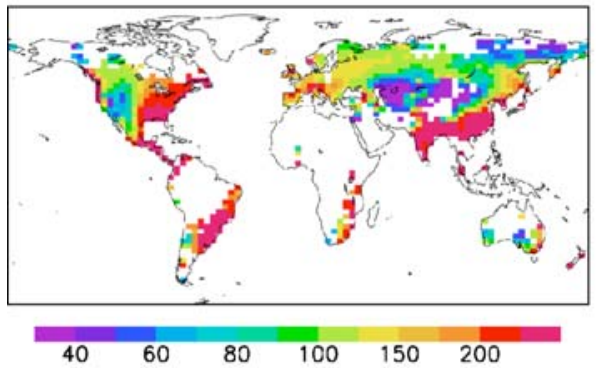

e CDD [days] HadEX data

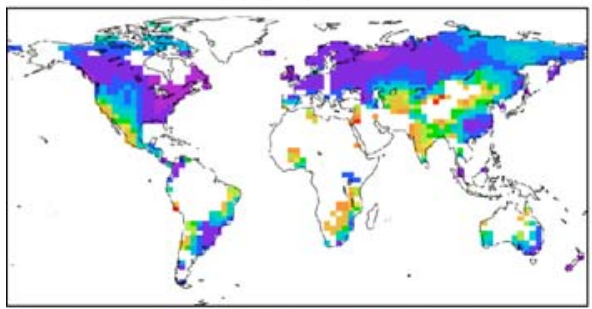

$\begin{array}{llllll}20 & 40 & 60 & 80 & 100 & 200\end{array}$ b Rx5day [mm] model data

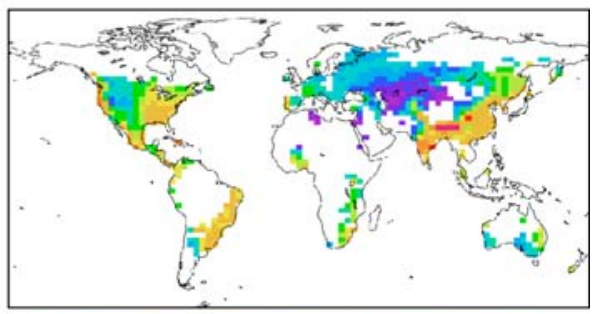

$\begin{array}{llllll}20 & 40 & 60 & 80 & 100 & 200\end{array}$

d R95p [mm] model data

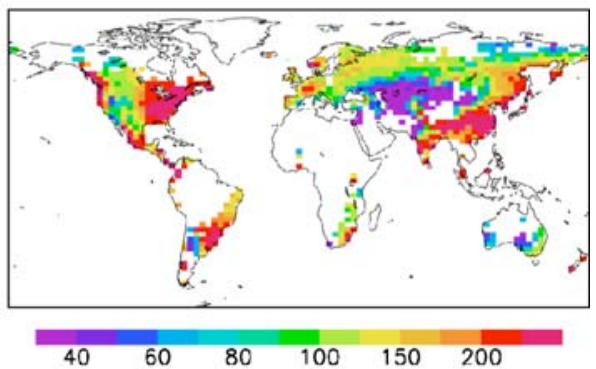

f CDD [days] model data

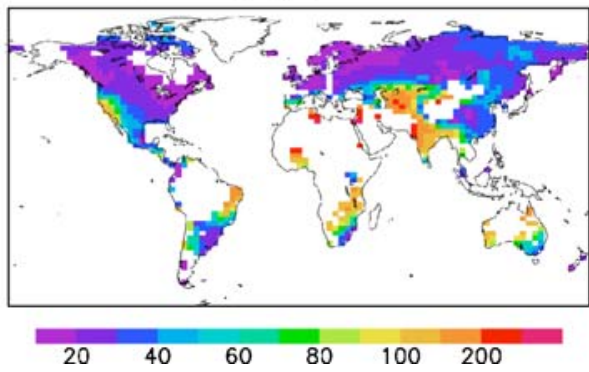

Fig. 3 As Fig. 1, but for the precipitation-based indices, maximum 5-day precipitation (a, b), 95th percentile of precipitation on wet days $(\mathbf{c}, \mathbf{d})$, and maximum number of consecutive dry days $(\mathbf{e}, \mathbf{f})$

The spatial pattern of the precipitation amount on very wet days (R95p) is very well captured (Fig. 3c,d), but an overestimation of the absolute values can be seen in the western part of North America and Northeast Asia. Furthermore, the model underestimates R95p around the Mediterranean Sea, in India and Southeast Asia, and in the eastern parts of Africa and Brazil. Although the model represents the total annual wet-day precipitation (PRCPTOT; not shown) well, it generally tends to underestimate extreme precipitation events as described by RX5day or R95p. This is also noticeable in other precipitation-based indices, such as maximum 1-day precipitation (RX1day) and very heavy precipitation days (R20; not shown). In comparison with the HadEX data, the model reveals some problems in describing the precipitation distribution in terms of the number of wet days and the precipitation intensity on wet days. For instance, the model simulates too many consecutive wet days (CWD) while the actual amount of precipitation is too little on the individual wet day as indicated by the index SDII (simple daily intensity; both not shown). The large-scale 
pattern of the number of consecutive dry days (CDD) is reasonably well captured (Fig. 3e,f). However, at high northern latitudes, CDD is systematically lower than observed. Moreover, a significant underestimation of CDD can be seen in some dry regions, such as the northern part of Mexico, where the model and HadEX data differ by up to 60 days. In India and in the region west of the Caspian Sea, on the other hand, the model overestimates CDD by more than 50 days, on average.

The temporal evolution of RX5day for three European regions is shown in Fig. 4a-c. In northern Europe, the HadEX time series generally falls within the ensemble spread of the model, except in the 1990s where the observed upward trend is not simulated by the model. In regions further south, RX5day is systematically too low. For example, in central Europe this underestimation amounts to $15 \mathrm{~mm}$, corresponding to $20 \%$, and in southern Europe it is about $25 \mathrm{~mm}$, corresponding to $28 \%$, on average. Similar to RX5day, the R95p index is very well simulated in northern Europe (Fig. 4f). Differences between the HadEX and the model data are more pronounced in central Europe (Fig. 4e) and become even larger in southern Europe (Fig. 4d), where the model underestimates R95p by approximately $50 \mathrm{~mm}$, corresponding to $30 \%$, on average. The inter-annual variability of R95p increases towards southern Europe in both the HadEX data and model simulations. The underestimation of extreme precipitation, especially in southern Europe, can also be seen in other indices, such as the maximum 1-day precipitation (RX1day), the simple daily intensity index (SDII), the
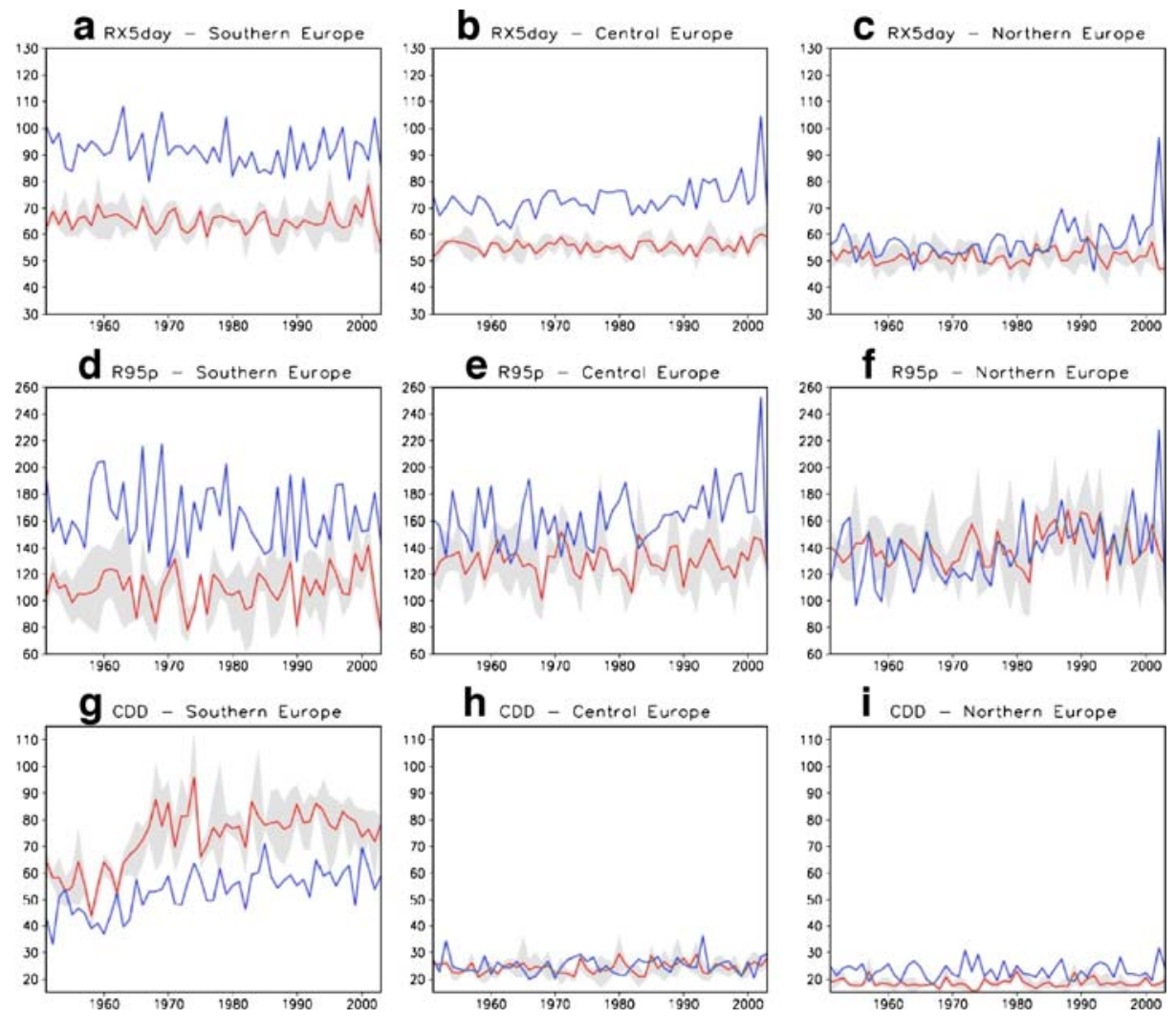

Fig. 4 As Fig. 2, but for the precipitation-based indices maximum 5-day precipitation (a, b, c; mm), 95th percentile of precipitation on wet days $(\mathbf{d}, \mathbf{e}, \mathbf{f} ; \mathbf{m m})$, and maximum number of consecutive dry days (g, h, $\mathbf{i}$; days) 
number of heavy precipitation days (R10) and the number of very heavy precipitation days (R20; not shown). The consecutive wet days (CWD; not shown) are well captured by the model in southern Europe but become increasingly overestimated at higher latitudes. The model represents the annual total wet-day precipitation (PRCPTOT; not shown) best in central Europe, but overestimates this index in northern Europe and underestimates it in southern Europe. The consecutive dry days (CDD) index shown in Fig. $4 \mathrm{~g}-\mathrm{i}$ is very well simulated in central Europe and reasonably well in northern Europe. The ensemble spread in northern Europe is very small and the model underestimates CDD by only a few days. In southern Europe, the model overestimates CDD by more than 20 days, corresponding to $30 \%$ on average, except in the 1950 s when the simulated CDD is closer to the observed one. However, the abrupt change in the simulated CDD is not a real effect but can be attributed to a changed masking of missing values in the HadEX data (cf., Section 4.1).

\subsection{Changes in extremes in future climate projections}

To detect changes in the indices for climate extremes in the climate projections for the twenty-first century, time intervals of 30 years at the end of the twentieth and the twentyfirst century, respectively, were chosen, and the time means for these periods were compared. The present-day climate state (1971-2000) was derived from the $20 \mathrm{C}$ ensemble, the future one (2071-2100) from the three ensemble members of the scenario runs A1B and $\mathrm{B} 1$, respectively. The statistical significance of the differences between these climate states was assessed through a non-parametric test as described in Roeckner et al. (2006a). The null hypothesis assumes that the difference $(\mathrm{DIFF}=$ Scenario-20C) is within the range of variations between randomly chosen 30-year segments of the control run (CON). This null hypothesis was tested against the alternative hypothesis that DIFF is larger than such random differences. The total of 500 years in CON was split into $n=16$ chunks of 30 years length. By forming differences across all available chunks $n(n-1) / 2=120$ differences were obtained. A Gaussian test was applied, where the distribution of these 120 differences for the individual indices in the control run were determined, and assessed whether the respective DIFF was larger than the 95th percentile of the CON distribution. In that case the null hypothesis was rejected with a risk of less than $5 \%$.

\subsubsection{Temperature}

The projected changes of temperature-based indices are shown in Fig. 5. In both scenarios, all changes in the displayed temperature indices are significant at the $95 \%$ confidence level, but the changes in A1B are generally more pronounced than in B1. The maximum Tmax (TXx) reveals the largest increase around the Mediterranean Sea, in southern Africa, in the northwestern part of South America but also in the far north of Siberia. Little increase can be seen in Scandinavia and in the adjacent part of Russia. The minimum Tmin (TNn), on the other hand, reveals the largest increase at high northern latitudes, i.e., in those regions where the increase in TXX is comparatively small. In the southern hemisphere, TNn does not increase by more than $3-4^{\circ} \mathrm{C}$, which is systematically smaller than the change in mean temperature (not shown). The tropical night index (TR) increases mostly around the Mediterranean Sea, in central America, central to southern Brazil, southern Africa and along the East coast of Australia. In both scenarios, tropical nights can be expected in regions like Canada and parts of Eurasia, which do not experience tropical nights under present climate conditions.

In the time series of temperature-based indices for three European regions (Fig. 6), distinguishable differences between the two scenarios cannot be seen before year 2040, 

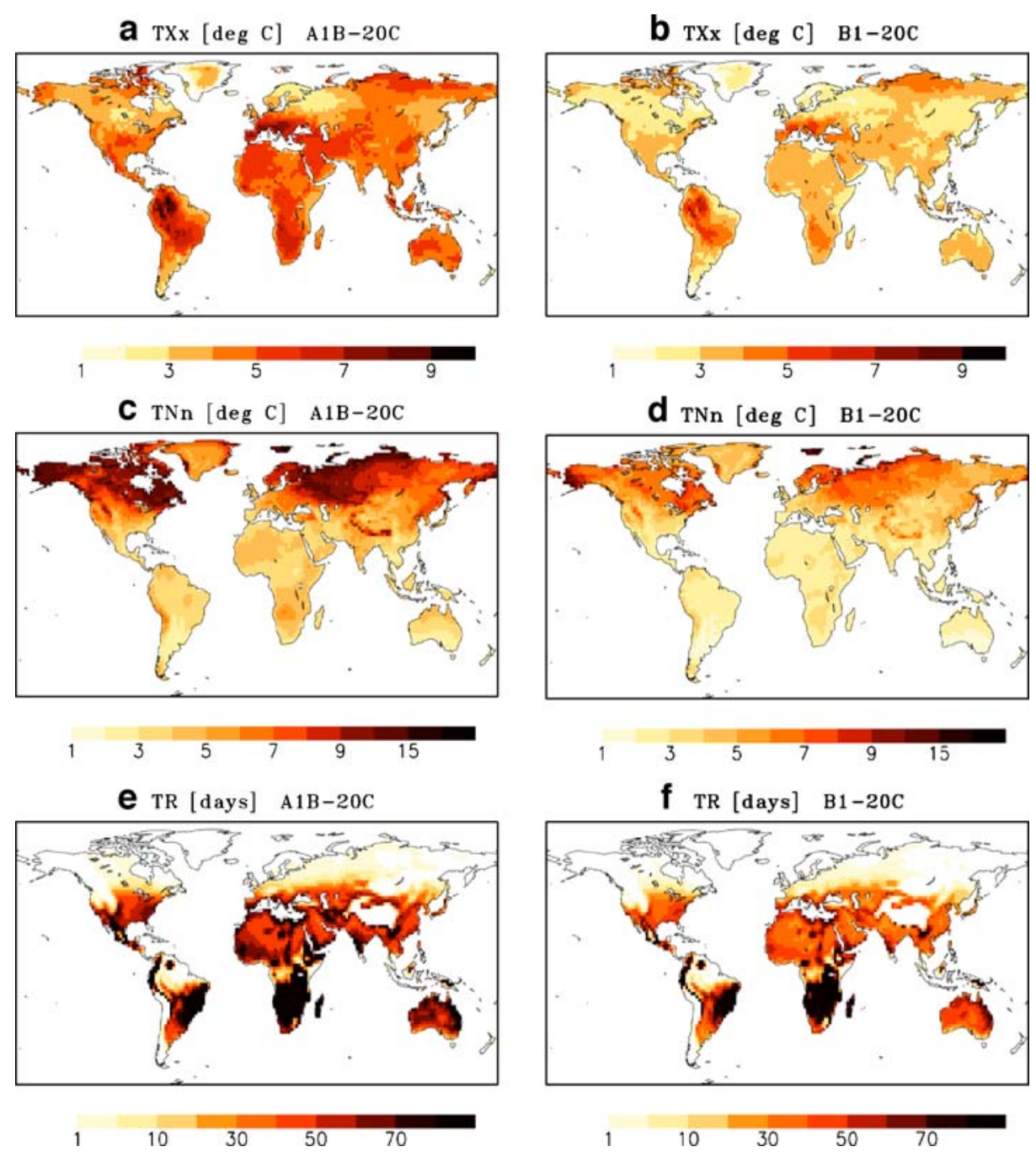

Fig. 5 Differences of temperature-based indices between the ensemble mean of (left) A1B (2071-2100) and 20C (1971-2000) and (right) B1 (2071-2100) and 20C (1971-2000) simulations. Shown are the respective differences for maximum Tmax (a, b), minimum Tmin $(\mathbf{c}, \mathbf{d})$ and tropical nights $(\mathbf{e}, \mathbf{f})$. All changes displayed in this figure are significant at the $95 \%$ confidence level

considering the ensemble spread indicated by shading around the ensemble mean. TXx increases mostly in southern Europe from about $37^{\circ} \mathrm{C}$ in the present climate to $42^{\circ} \mathrm{C}$ (B1) and $44^{\circ} \mathrm{C}(\mathrm{A} 1 \mathrm{~B})$, respectively, in year 2100 . In central Europe, the trend of TXx is similar with an increase of $5^{\circ} \mathrm{C}$ in $\mathrm{B} 1$ and $6^{\circ} \mathrm{C}$ in $\mathrm{A} 1 \mathrm{~B}$ until year 2100. In northern Europe, TXx rises by only $2-3^{\circ} \mathrm{C}$, and the changes remain similar in both scenarios even beyond the year 2040. The regional changes of TNn are opposite to those of TXx. In contrast to TXx, the rise in $\mathrm{TNn}$ is most pronounced in northern Europe, from $-27^{\circ} \mathrm{C}$ in the present climate to approximately $-19^{\circ} \mathrm{C}$ in $\mathrm{B} 1$ and $-18^{\circ} \mathrm{C}$ in $\mathrm{A} 1 \mathrm{~B}$ until the end of this century. In central and southern Europe, $\mathrm{TNn}$ rises by about $4^{\circ} \mathrm{C}$ in $\mathrm{B} 1$ and $6-7^{\circ} \mathrm{C}$ in $\mathrm{A} 1 \mathrm{~B}$. It is interesting to note that, probably as a result of large natural variability on the regional scale, the ensemble 

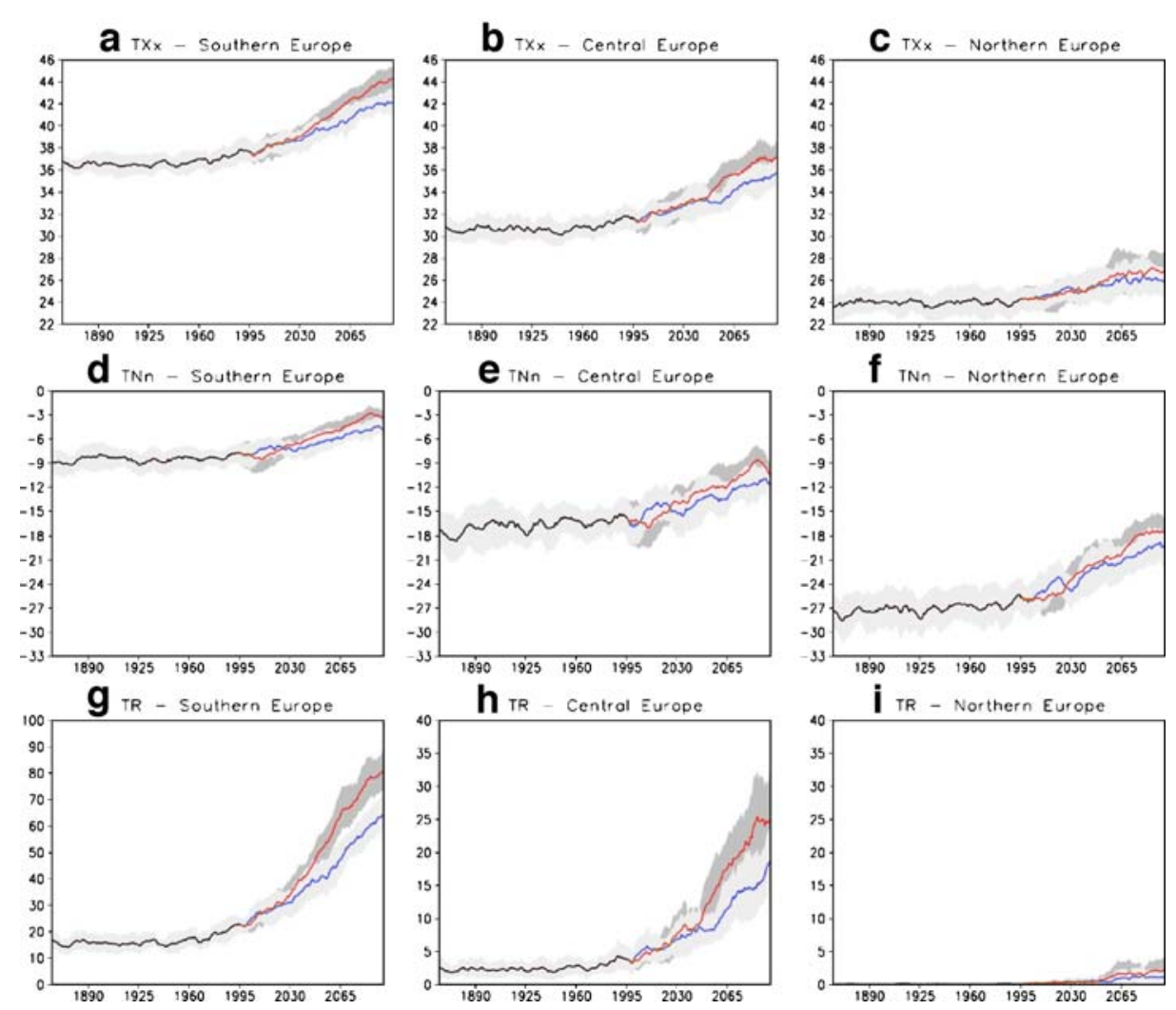

Fig. 6 Time series (1860-2100) of spatially averaged (land only) temperature-based indices for three regions in Europe (cf., Table 2) in 20C (black), A1B (red) and B1 (blue) model simulations. Shown are the maximum $\operatorname{Tmax}\left({ }^{\circ} \mathrm{C}\right)$ in the three regions $(\mathbf{a}, \mathbf{b}, \mathbf{c})$, the minimum $\operatorname{Tmin}\left(\mathbf{d}, \mathbf{e}, \mathbf{f} ;{ }^{\circ} \mathrm{C}\right)$ and the tropical nights $(\mathbf{g}, \mathbf{h}, \mathbf{i} ;$ days). Displayed are the respective ensemble means. The spread in the ensemble members is indicated by light (B1) and dark (A1B) shading, respectively. Data are smoothed by 10-year running means

mean changes of TNn until about year 2025 are larger in B1 than in A1B. Further it should be pointed out, that both TXx and TNn increase at a similar rate in southern and central Europe (about $4-5^{\circ} \mathrm{C}$ in $\mathrm{B} 1$ and $6-7^{\circ} \mathrm{C}$ in $\mathrm{A} 1 \mathrm{~B}$ ). However, in northern Europe $\mathrm{TNn}$ increases much faster (by up to $9^{\circ} \mathrm{C}$ in $\mathrm{A} 1 \mathrm{~B}$ ) than TXx (by only $3^{\circ} \mathrm{C}$ in $\mathrm{A} 1 \mathrm{~B}$ ). The most striking increase of tropical nights is simulated for southern Europe, from about 15 nights per year in the present climate up to 65 nights in B1 and 80 nights in A1B until the end of this century. In central Europe, the TR increases from about 3 nights per year to 18 in B1 and 25 in A1B. A widening of the ensemble spread towards the end of the twenty-first century is also noticeable in that region, indicating that the inter-annual variability in the number of tropical nights is expected to increase. Even northern Europe, where no tropical nights occur in present climate, will experience a few tropical nights per year at the end of the twenty-first century.

\subsubsection{Precipitation}

As apparent from Fig. 7a-d, RX5day and R95p, which describe the wet part of precipitation extremes, show a significant increase in many regions of the world. The 

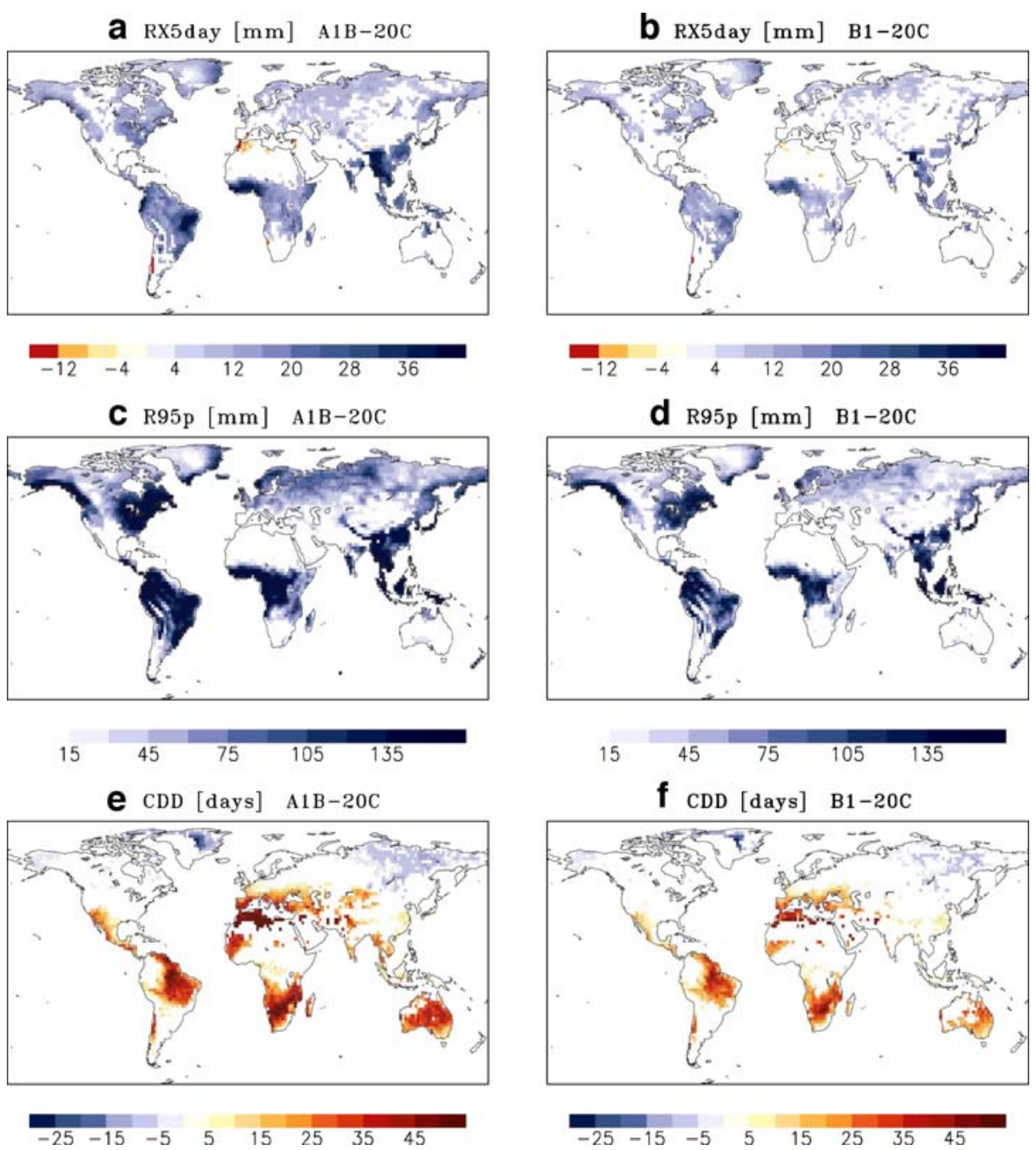

Fig. 7 As Fig. 5, but for projected changes in the precipitation-based indices maximum 5-day precipitation (a, b), 95th percentile of precipitation on wet days $(\mathbf{c}, \mathbf{d})$, and maximum number of consecutive dry days $(\mathbf{e}, \mathbf{f})$. Changes that are statistically insignificant at the $95 \%$ confidence level are not displayed (white areas)

changes are more pronounced in A1B than in B1. The largest increase can be found at lower latitudes, in the eastern part of North America and along the West coast of Canada. Further, the R95p increases strongly in the northern part of Eurasia. A significant decrease of RX5day is found only in a few regions, for example, in southern Spain, Morocco and along the coast of southern Chile. The consecutive dry day (CDD) index increases significantly in regions around the Mediterranean Sea, especially along the African coast (Fig. 7e,f). Further increases of CDD can be found in Australia, southern Africa, in the northeastern part of South America as well as along the Pacific coast of Central and South America (especially Chile). The CDD changes are systematically larger in A1B than in B1 and also the regions with significant changes are more extended in A1B than in B1 (e.g., Australia). In a few regions of the northern hemisphere, namely in parts of Alaska, Siberia and Greenland, the number of consecutive dry days tends to decrease in both scenarios. 
According to the time series of precipitation-based indices for three European regions (Fig. 8) RX5day decreases slightly in the twenty-first century in southern Europe, whereas R95p shows hardly any trend. In northern Europe, however, there is a marked increase of both RX5day and R95p. In A1B, RX5day increases by about $9 \mathrm{~mm}$ until the end of this century, and the R95p rises by approximately $90 \mathrm{~mm}$. This corresponds to an increase of $17 \%$ in RX5day and 64\% in R95p. In general, the RX5day differences between B1 and A1B are not pronounced in the three European regions. For R95p, differences in the ensemble means are visible in northern Europe from year 2040 onward, and in central Europe from year 2060 onward, but there is a large overlap of the respective ensemble spreads during the whole simulation period. In central Europe, RX5day and R95p increase as well, but not as strongly as in northern Europe. Distinguishable differences between the two scenarios cannot be seen until the very end of the scenario runs, where the indices undergo a sharp decrease in the last 10 years of the B1 scenario. In the A1B scenario, RX5day and R95p continue to rise until the end of the twenty-first century whereas RX5day rises by about $7 \mathrm{~mm}$, corresponding to an increase of $13 \%$, and R95p rises by about $60 \mathrm{~mm}(46 \%)$. In contrast to the wet extreme precipitation events, CDD is projected to increase substantially in southern Europe, from approximately 75 days in the present climate to 105 days in $\mathrm{B} 1$ and 115 days in A1B. This means that the longest dry period
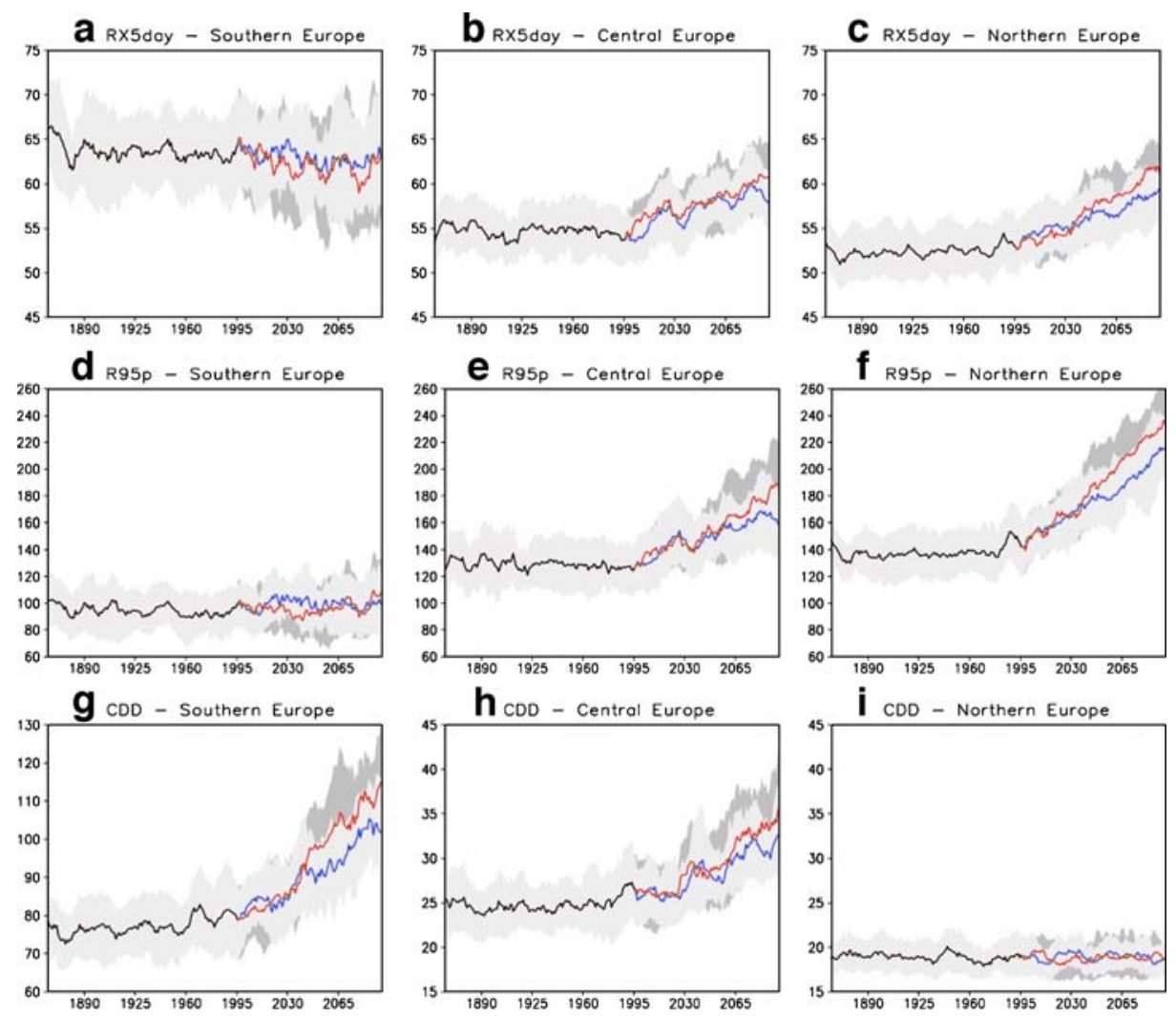

Fig. 8 As Fig. 6, but for the temporal evolution of the precipitation-based indices maximum 5-day precipitation $(\mathbf{a}, \mathbf{b}, \mathbf{c} ; \mathbf{m m})$, 95th percentile of precipitation on wet days $(\mathbf{d}, \mathbf{e}, \mathbf{f} ; \mathbf{m m})$, and maximum number of consecutive dry days ( $\mathbf{g}, \mathbf{h}, \mathbf{i}$; days) 
within a year is prolonged by 1 (1.5) months at the end of this century in B1 (A1B). Differences between the scenarios do not emerge before the year 2040. In northern Europe, CDD has no trend and stays at about 19 days per year on average in both scenarios. In central Europe, CDD increases by approximately 7 days in $\mathrm{B} 1$ and 10 days in A1B, whereas significant differences between the scenarios cannot be distinguished since the respective ensemble ranges continue to overlap until the end of the twenty-first century.

\subsubsection{Seasonal changes}

In order to analyze seasonal changes in TXx, TNn and RX5day, 30-year monthly means of these indices were calculated at each grid point for the 20C simulations (1971-2000) and for the A1B and B1 scenarios (2071-2100), respectively, and the results for the three European regions were then obtained by spatial averaging (land only). Since three ensemble members are available for both the $20 \mathrm{C}$ experiments and the scenarios, it is possible to compute $3^{2}$ differences between the respective scenario and the $20 \mathrm{C}$ experiment. Results are displayed for both the ensemble mean differences for every month and for the respective standard deviations obtained from all nine individual differences.

Figure 9 shows the simulated changes in the climatological annual cycle of temperaturebased indices for the three European regions. TXx and TNn increase in all months and in all
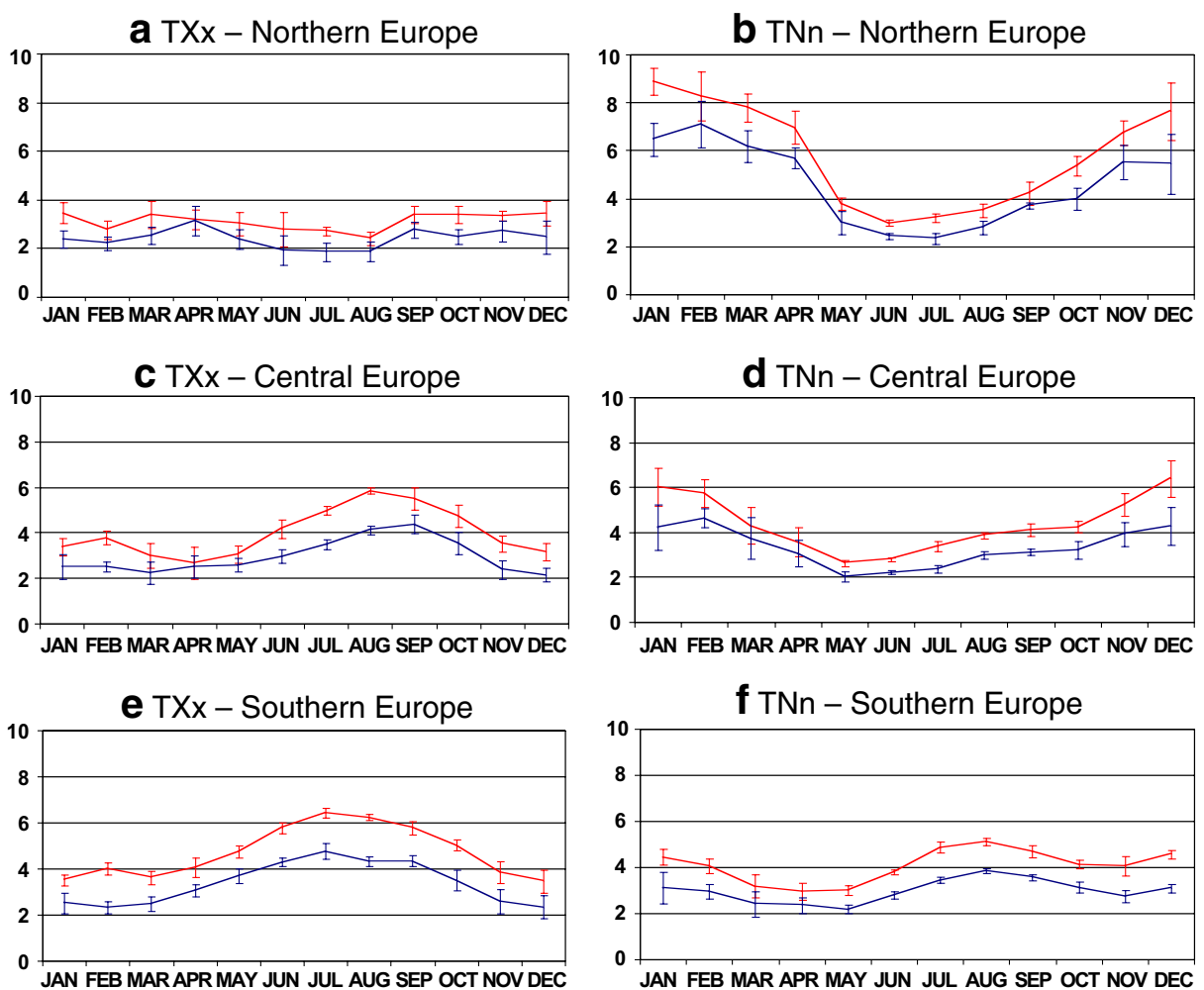

Fig. 9 Simulated changes in the climatological annual cycle of maximum $\operatorname{Tmax}\left(\mathbf{a}, \mathbf{c}, \mathbf{e} ;{ }^{\circ} \mathrm{C}\right)$ and minimum $\mathrm{Tmin}$ (b, d, f; ${ }^{\circ} \mathrm{C}$ ) for three regions in Europe (cf., Table 2). Red Differences between A1B (2071-2100) and 20C (1971-2000). Blue Differences between B1 (2071-2100) and 20C (1971-2000). The standard deviation $( \pm 1 \sigma)$, calculated from nine differences between the respective ensemble members, is indicated by vertical bars

Springer 
European regions in both scenarios, but the changes are generally seasonally dependent. An exception is TXx in northern Europe, which increases more or less constantly throughout the year. In contrast, TNn in northern Europe shows the largest increase (up to $9^{\circ} \mathrm{C}$ in $\mathrm{A} 1 \mathrm{~B}$ ) in the winter months, and the smallest increase (down to $3^{\circ} \mathrm{C}$ in $\mathrm{A} 1 \mathrm{~B}$ ) in the summer months. The standard deviations are also largest in winter and smallest in summer. Significant differences between A1B and B1 are evident, as indicated by the separation of the blue and red bars in almost all months. In central Europe, the changes in the annual cycles of TXx and TNn are largely out of phase. TXx increases predominantly from July to October (above $5^{\circ} \mathrm{C}$ in A1B), whereas TNn reveals the largest increase in the winter months (around $6^{\circ} \mathrm{C}$ in A1B). The increase in TNn is relatively small in May and June (less than $3^{\circ}$ $\mathrm{C})$, where also the smallest standard deviations occur. The smallest increase of TXx can be found in spring $\left(3^{\circ} \mathrm{C}\right.$ in $\left.\mathrm{A} 1 \mathrm{~B}\right)$ and from late autumn to spring $\left(2.5^{\circ} \mathrm{C}\right.$ in $\left.\mathrm{B} 1\right)$. Standard deviations of TXx overlap in January and in spring. The smallest standard deviations, in both scenarios, occur in July and August. In southern Europe, the changes in the annual cycles of TXx and TNn differ as well. The largest increase in TXx is found from June to September, which is around $6^{\circ} \mathrm{C}$ in $\mathrm{A} 1 \mathrm{~B}$ and around $4.5^{\circ} \mathrm{C}$ in $\mathrm{B} 1$. The standard deviations

Fig. 10 As Fig. 9, but for the precipitation-based index maximum 5-day precipitation ( $\mathrm{mm}$ ). a RX5day, Northern Europe; b RX5day, Central Europe; c RX5day, Southern Europe

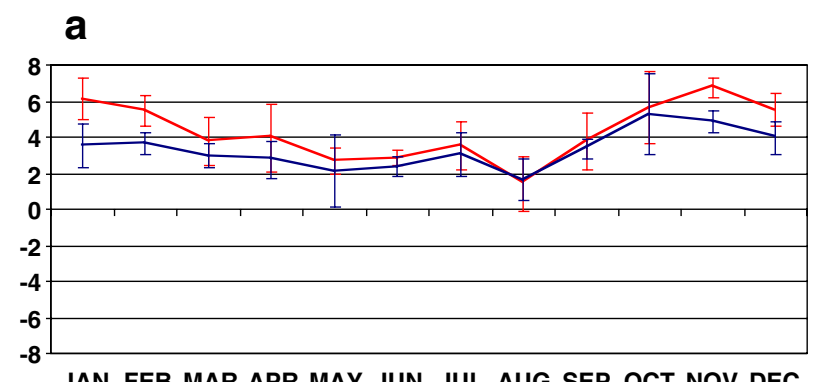

JAN FEB MAR APR MAY JUN JUL AUG SEP OCT NOV DEC

b

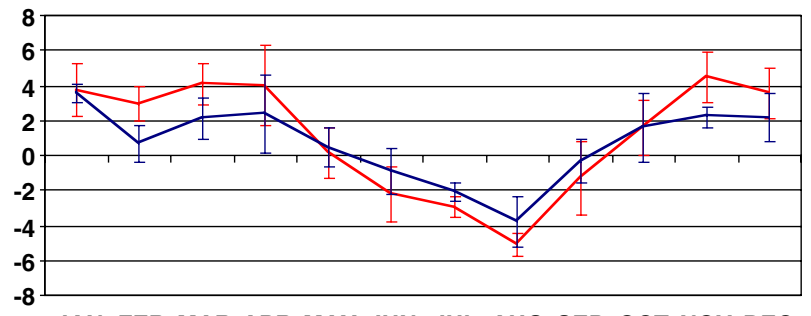

JAN FEB MAR APR MAY JUN JUL AUG SEP OCT NOV DEC

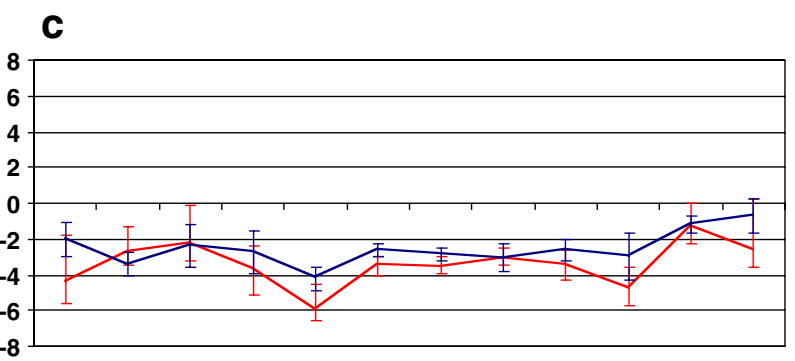
JAN FEB MAR APR MAY JUN JUL AUG SEP OCT NOV DEC 
do not overlap throughout the year, i.e., the scenarios are well separated. In the winter months, the increase in TXx is substantially smaller than in summer $\left(2.5^{\circ} \mathrm{C}\right.$ in $\mathrm{B} 1$ and $3.5-$ $4^{\circ} \mathrm{C}$ in $\mathrm{A} 1 \mathrm{~B}$ ). The increase in $\mathrm{TNn}$ is smallest in spring (around $2.5^{\circ} \mathrm{C}$ in $\mathrm{B} 1$ and $3^{\circ} \mathrm{C}$ in $\mathrm{A} 1 \mathrm{~B}$ ). The largest increase in TNn is found between July and September (almost $4^{\circ} \mathrm{C}$ in $\mathrm{B} 1$ and $5^{\circ} \mathrm{C}$ in $\mathrm{A} 1 \mathrm{~B}$ ), but $\mathrm{TNn}$ remains relatively high in winter as well (about $4.5^{\circ} \mathrm{C}$ in $\mathrm{A} 1 \mathrm{~B}$ ). The standard deviations of TNn do not overlap except for March and April. The standard deviations of TXx and TNn are, in general, smallest in southern Europe and largest in northern Europe due to the north-south gradient in inter-annual variability, especially in the winter months.

According to Fig. 10a, which shows the simulated changes in the climatological annual cycle of the precipitation-based index RX5day in northern Europe, the largest increase of about $6 \mathrm{~mm}$ in A1B (corresponding to about 20\% on average) can be found in late autumn to winter (October-February). In B1 the largest increase of 4-5 mm, corresponding to $15 \%$ on average, occurs from October to December. The standard deviations in both scenarios do not overlap in January, February and November. In both scenarios, the smallest increase of about $2 \mathrm{~mm}$, corresponding to 6\%, is found in August. In central Europe (Fig. 10b), RX5day increases between October and April by about $4 \mathrm{~mm}(14 \%)$ in A1B and $2 \mathrm{~mm}$ $(7 \%)$ in B1, and it decreases in the summer months by up to $5 \mathrm{~mm}(20 \%)$ in August (A1B). These changes are more pronounced in A1B, but generally, except for February and November, the standard deviations in the scenarios do overlap. In May and September the changes of RX5day are insignificant. In southern Europe (Fig. 10c), RX5day decreases in both scenarios. In A1B, this decrease is more pronounced than in B1, but the standard deviations do overlap in all months. The largest decreases in A1B can be found in May $(6 \mathrm{~mm}$ or $32 \%)$ and October $(4.8 \mathrm{~mm}$ or $17 \%)$. In B1, the smallest decrease of RX5day is found in December (1 $\mathrm{mm}$ or 3\%) whereas the largest decrease, as in A1B, is found in May (4 $\mathrm{mm}$ or $21 \%$ ).

\section{Discussion and concluding remarks}

The comparison with the HadEX indices shows that the ECHAM5/MPI-OM model, in general, is able to capture the climatological large-scale patterns of extreme temperature and precipitation indices with good fidelity, although the quality of the simulations depends on the index and region under consideration. For example, the maximum summer temperatures, TXx, are severely underestimated by up to $10^{\circ} \mathrm{C}$ at high northern latitudes, whereas the minimum Tmin (TNn) pattern is realistically simulated. The negative bias of TXx at high northern latitudes may be caused by an overly strong westerly flow in boreal summer (Roeckner et al. 2006b) with enhanced advection of relatively wet and cold maritime air masses and, consequently, high cloud amount and precipitation (Hagemann et al. 2006). The simulated minimum winter temperatures $\mathrm{TNn}$, on the other hand, are similar to those of HadEX due to the fact that the large-scale circulation in boreal winter is well simulated (Roeckner et al. 2006b). In Europe, the biases mentioned above are obvious as well. Whereas TNn is very well simulated in southern, central, and northern Europe, TXx is slightly underestimated in central Europe but severely underestimated in northern Europe. As to be expected, there is a marked meridional gradient in TR with values close to zero in northern Europe and about 25 days in southern Europe in both the simulations and observations. At lower latitudes the temperature-based indices are in good agreement with the HadEX indices. This applies to both TXx and TNn, whereas the number of tropical nights, TR, is slightly on the high side. 
The large-scale patterns of precipitation-based indices, i.e., the 5-day maximum (RX5day) and 95th percentile of precipitation (R95p) as well as the maximum number of consecutive dry days (CDD), are similar to the observed ones. However, in most regions both RX5day and R95p are smaller than observed. To some extent, this might be due to methodological differences in the computation of observation-based and model-based indices, respectively (see Section 3). The model input available for calculating the indices represents averages for grid-box areas of up to some $40,000 \mathrm{~km}^{2}$, whilst the observed indices were computed from data at measurement sites and gridded thereafter. Very likely, the former method implies a stronger smoothing of extremes than the latter, in particular for spatially inhomogeneous variables like precipitation. In addition, regional biases in the simulated mean climate state do contribute to biases in precipitation extremes as well. For example, in the Mediterranean region, the dry bias in the mean state is reflected in the under-representation of RX5day and R95p and overestimation of CDD. In most regions, the number of consecutive wet days is higher than observed, whereas the mean rain intensity is too low.

In conclusion, the simulated broad-scale patterns of temperature- and precipitation-based indices are in good agreement with those obtained from the HadEX data, but the model biases can be substantial in certain regions (e.g., TXx at northern high latitudes, precipitation-based indices in the Mediterranean region).

In the climate projections for the twenty-first century, all temperature-based indices show a significant increase worldwide at the end of this century. Similarly, extreme precipitation (RX5day and R95p) is projected to increase significantly in most regions of the world, especially in those regions that are relatively wet already under present climate conditions (middle and high northern latitudes, Southeast Asia, Indonesia, Central Africa, South America). Analogously, CDD increases particularly in those regions that are already relatively dry under present climate conditions (Mediterranean countries, California and northern Mexico, Mauritania, South Africa, Australia). An exception is the northeastern part of South America where all precipitation indices, RX5day, R95p, and CDD, increase significantly. In general, the differences between humid and arid climate zones tend to increase under global warming. This has been found already for the changes in the mean state (e.g., Cubasch et al. 2001) but it seems to apply to the changes in the precipitation extremes as well.

Northern high latitudes are affected by a strong increase of Tmin, which causes an extension of the growing season length and a substantial reduction in the number of frost days in both climate scenarios. This has a major impact on the terrestrial biota (Parmesan et al. 2000) and on the permafrost soils. The northern part of Siberia will be mostly affected since both extremes of the temperature distribution, TXX and TNn, increase substantially in that region. The fact that TNn increases faster than TXx, especially in northern Europe, can be related to a northward shift of the westerly wind regime during winter months causing enhanced advection of warm and moist maritime air, higher cloud amount and reduced nighttime cooling in the winter months. This finding is consistent with the results obtained by Easterling et al. (1997) and Giorgi et al. (2001). The substantial rise of TNn in winter in central and northern Europe leads to less snowfall and a shorter retention period of snow, especially in the low mountain ranges in central Europe. This will have a major impact on tourism in those regions. On the other hand, in southern and central Europe, TXx rises predominantly in summer and early autumn, which is consistent with the prolongation of dry spells in these regions.

Agriculture will be diversely affected in northern and southern Europe, respectively. In northern Europe, higher temperatures and a longer growing season length are favorable 
conditions for agriculture, whereas in southern Europe extensive irrigation will be required because of higher temperatures, less precipitation, and prolonged dry spells in the future climate.

There is also a significant increase worldwide in the number of tropical nights. At the end of this century, a tropical night will not be the exception in southern Europe, as in the present climate, but the rule in all summer months. This intensifies the heat stress on humans and other living organisms provoked by increasing heat waves or daytime temperatures (Meehl and Tebaldi 2004). This heat stress is further enhanced by the increasing number of consecutive dry days. These changes in climate extremes will have a severe impact on living conditions, water supply, and agriculture in the regions around the Mediterranean Sea. Northern regions, where no tropical nights occur in the present climate, will face an increasing number of tropical nights as well, which will occur in summer during sporadic heat wave periods. This will demand socio-economic adaptation measures of northern populations that are not used to tropical nights, e.g. enhanced cooling systems and special health care for elderly people and children.

The regional analysis of the annual cycle indicates that the increase of maximum 5-day precipitation in central and northern Europe occurs predominantly in the winter months, caused primarily by a northward shift of the storm tracks (Bengtsson et al. 2006). In central Europe, RX5day decreases during summer, especially in August, induced by an eastward extension of the Azores high, which leads to a reduction of moisture supply from the Atlantic and thus causes an intense drying in the Mediterranean region (Giorgi et al. 2001). The prolongation of dry spells will also affect central Europe. In general, the regions with extended dry spells broaden and, therefore, regions endangered by desertification grow. In particular, the Mediterranean regions will face longer drought conditions lasting for more than 3 months, especially in summer. In some studies, heavy rainstorm events (smaller in scale than RX5day) will become more probable (Christensen and Christensen 2003). This amplifies the risk of erosion of dried-out, uncovered soils in these regions. The northern part of Europe will not be endangered by longer dry periods, but the increase of RX5day enforces the risk of flooding.

A crucial point to ask is to what extent the simulated changes might be affected by the model biases identified in the comparison with the HadEX indices. For example, is the modest increase in TXX at high northern latitudes affected by the negative bias in these regions or is it just the result of enhanced advection of moist maritime air in the warmer climate? Similarly, is the enhanced warming and drying in the Mediterranean countries partially caused by the dry model bias in these regions? Is the projected increase in RX5day and R95p too small because these indices are generally underestimated compared to the HadEX data? To answer these questions, a multi-model study would be required allowing to investigate the impact of model biases on the robustness of the response. Nevertheless, it seems fair to conclude that more confidence should be placed in the projections of those indices that are realistically captured by the model under present-day climate conditions.

In many respects, the results found in our simulations are consistent with the multimodel study of Tebaldi et al. (2006) and other studies on changes in extremes of temperature and precipitation (e.g., Meehl et al. 2000; Easterling et al. 2000a,b; Meehl and Tebaldi 2004). This study has further shown that, in addition to the large-scale patterns, it is useful to focus on regional scales such as the three European regions, which show distinct differences in the temporal evolution of the extreme indices on both annual and seasonal time scales. Many of these changes are likely to be related to changes in the large-scale atmospheric circulation (e.g., Haylock and Goodness 2004; Cassou et al. 2005). The 
robustness of the correlations between the large-scale flow and extreme indices will be investigated in a separate study.

Acknowledgements We thank Lisa Alexander (Department of Geography and Environmental Science at Monash University, Melbourne) and John Caesar (Met Office, Hadley Centre for Climate Prediction and Research) for providing the HadEX indices and for the helpful suggestions concerning the analysis of the indices. We thank three anonymous reviewers for their constructive comments, which greatly helped to improve this paper. Further, we acknowledge the International Max Planck Research School for Earth System Modeling for financing this work.

\section{References}

Alexander LV, Zhang X, Peterson TC, Caesar J, Gleason B, Klein Tank A, Haylock M, Collins D, Terwin B, Rahimzadeh F, Tagipour A, Ambenje P, Rupa Kumar K, Revadekar J, Griffiths G, Vincent L, Stephenson D, Burn J, Aguilar E, Brunet M, Taylor M, New M, Zhai P, Rusticucci M, Vazquez-Aquirre JL (2006) Global observed changes in daily climate extremes of temperature and precipitation. J Geophys Res 111:D05109

Bengtsson L, Hodges KI, Roeckner E (2006) Storm tracks and climate change. J Climate 19:3518-3543

Cassou C, Terray L, Phillips AS (2005) Tropical Atlantic influence on European heat waves. J Climate 18:2805-2811

Christensen JH, Christensen OB (2003) Climate modelling: severe summertime flooding in Europe. Nature 421:805-806

Cubasch U, Meehl UA, Boer GJ, Stouffer RJ, Dix M, Noda A, Senior CA, Raper S, Yap, KS (2001) Projections of future climate change. In: Houghton JT, Ding Y, Griggs DJ, Noguer M, van der Linden P, Dai X, Maskell K, Johnson CI (eds) Climate change 2001: the scientific basis. Contribution of working group I to the third Assessment Report of the Intergovernmental Panel on Climate Change Cambridge University Press, $\mathrm{p} 881$

Easterling DR, Horton B, Jones PJ, Peterson TC, Karl TR, Parker DE, Salinger MJ, Razuvayev V, Plummer N, Jamason P, Folland CK (1997) Maximum and minimum trends for the globe. Science 277:364-367

Easterling DR, Meehl GA, Parmesan C, Changnon SA, Karl TR, Mearns LO (2000a) Climate extremes: observations, modeling, and impacts. Science 289:2068-2074

Easterling DR, Evans JL, Groisman PY, Karl TR, Kunkel KE, Ambenje P (2000b) Observed variability and trends in extreme climate events: a brief review. Bull Am Meteorol Soc 81:417-425

Folland CK, Miller C, Bader D, Crowe M, Jones P, Plummer N, Richman M, Parker DE, Rogers J, Scholefield P (1999) Workshop on indices and indicators for climate extremes, Asheville, NC, USA, 3-6 June 1997. Breakout group C: temperature indices for climate extremes. Clim Change 42:31-43

Frich P, Alexander LV, Della-Marta P, Gleason B, Haylock M, Klein Tank AM, Peterson T (2002) Observed coherent changes in climate extremes during the second half of the twentieth century. Clim Res 19:193-212

Giorgi F, Whetton PH, Jones RG, Christensen JH, Mearns LO, Hewitson B, von Storch H, Francisco R, Jack C (2001) Emerging patterns of simulated regional climatic changes for the 21 st century due to anthropogenic forcings. Geophys Res Lett 28:3317-3320

Hadley Centre Observational Datasets (2006) Met Office, Hadley Center for Climate Prediction and Research, Devon, UK. http://www.hadobs.org. Cited 11 January 2006

Hagemann S, Arpe K, Roeckner E (2006) Evaluation of the hydrological cycle in the ECHAM5 model. J Climate 19:3810-3827

Haylock MR, Goodness CM (2004) Inter-annual variability of European extreme winter rainfall and links with mean large-scale circulation. Int J Climatol 24:759-776

Houghton JT, Ding Y, Griggs DJ, Noguer M, van der Linden P, Dai X, Maskell K, Johnson CI (eds) (2001) Climate change 2001: the scientific basis. Contribution of working group I to the third assessment report of the Intergovernmental Panel on Climate Change. Cambridge University Press, Cambridge, $\mathrm{UK}, \mathrm{p} 881$

Jungclaus, JH, Keenlyside N, Botzet M, Haak H, Luo J-J, Latif M, Marotzke J, Mikolajewicz U, Roeckner E (2006) Ocean circulation and tropical variability in the coupled model ECHAM5/MPI-OM. J Climate 19:3952-3972 
Karl TR, Jones PD, Knight RW, Kukla G, Plummer N, Razuvayev V, Gallo KP, Lindseay J, Charlson RJ, Peterson TC (1993) A new perspective on recent global warming: Asymmetric trends of daily maximum and minimum temperature. Bull Am Meteorol Soc 74(6):1007-1023

Karl TR, Nicholls N, Ghazi A (1999) CLIVAR/GCOS/WMO Workshop on indices and indicators for climate extremes. Workshop summary. Clim Change 42:3-7

Kiktev D, Sexton DMH, Alexander L, Folland CK (2003) Comparison of modeled and observed trends in indices of daily climate extremes. J Climate 16:3560-3571

Klein Tank AM (2004) Changing temperature and precipitation extremes in Europe's climate of the 20th Century. Dissertation, University Utrecht, The Netherlands

Klein Tank AM, Koennen GP (2003) Trends in indices of daily temperature and precipitation extremes in Europe, 1946-99. J Climate 16:3665-3680

Marsland SJ, Haak H, Jungclaus JH, Latif M, Roeske F (2003) The Max Planck Institute global ocean/sea ice model with orthogonal curvilinear coordinates. Ocean Model 5:91-127

Meehl GA, Tebaldi C (2004) More intense, more frequent, and longer lasting heat waves in the 21 st century. Science 305:994-997

Meehl GA, Zwiers F, Evans J, Knutson T, Mearns L, Whetton P (2000) Trends in extreme weather and climate events: issues related to modeling extremes in projections of future climate change. Bull Am Meteorol Soc 81:427-436

Nakicenovic N, Alcamo J, Davis G, de Vries B, Fenhann J, Gaffin S, Gregory K, Gruebler A, Jung TY, Kram T, La Rovere EL, Michaelis L, Mori S, Morita T, Pepper W, Pitcher H, Price L, Riahi K, Roehrl A, Rogner HH, Sankovski A, Schlesinger M, Shukla P, Smith S, Swart R, van Rooijen S, Victor N, Dadi Z (2000) Special report on emission scenarios: a special report of working group III of the Intergovernmental Panel on Climate Change. Cambridge University Press, Cambridge, UK, p 599

Nicholls N, Murray W (1999) Workshop on indices and indicators for climate extremes, Asheville, NC, USA, 3-6 June 1997. Breakout group B: precipitation. Clim Change 42:23-29

Parmesan C, Root TL, Willig MR (2000) Impacts of extreme weather and climate on terrestrial biota. Bull Am Meteorol Soc 81:443-450

Peterson TC (2005) Climate change indices. WMO Bull 54(2):83-86

Roeckner E, Baeuml G, Bonventura L, Brokopf R, Esch M, Giorgetta M, Hagemann S, Kirchner I, Kornblueh L, Manzini E, Rhodin A, Schlese U, Schulzweida U, Tompkins A (2003) The atmospheric general circulation model ECHAM5. Part 1: Model description. Report 349. Max Planck Institute for Meteorology, Hamburg, Germany

Roeckner E, Stier P, Feichter J, Kloster S, Esch M, Fischer-Bruns I (2006a) Impact of carbonaceous aerosol emissions on regional climate change. Clim Dyn 27:553-571

Roeckner E, Brokopf R, Esch M, Giorgetta M, Hagemann S, Kornblueh L, Manzini E, Schlese U, Schulzweida U (2006b) Sensitivity of simulated climate to horizontal and vertical resolution in the ECHAM5 atmosphere model. J Climate 19:3771-3791

Tebaldi C, Hayhoe K, Arblaster JM, Meehl GA (2006) Going to extremes, an intercomparison of modelsimulated historical and future changes in extreme events. Clim Change 79:185-211

Zhang X, Hegerl G, Zwiers FW, Kenyon J (2005) Avoiding inhomogeneity in percentile-based indices of temperature extremes. J Climate 18:1641-1651 